\title{
Dust exposure, pneumoconiosis, and mortality of coalminers
}

\author{
B G MILLER AND M JACOBSEN
}

From the Institute of Occupational Medicine, Edinburgh EH8 9SU, UK

ABSTRACT General mortality in approximately 25000 British coalminers over 22 year periods ending in 1980 was $13 \%$ lower on average than in English and Welsh men in the same regions of Britain. There were significant within region variations between collieries, and standardised mortality ratios increased during the later years of the follow up, approaching or slightly exceeding 100 in most of the 20 coalmines studied. Age specific comparisons of 22 year survival rates were made in subgroups. Relative risks of death from all non-violent causes for men with the earliest stage of progressive massive fibrosis (PMF category A), compared with risks in miners with no pneumoconiosis (category $\mathrm{O}$ ), ranged from 1.2 in those aged 55-64 initially to 3.5 for those aged 25-34. Mortality in miners with higher categories of PMF (B or C) was even more severe. Survival rates in men with category 1 simple pneumoconiosis were about $2 \%$ to $3 \%$ lower than in miners with radiographs classified as category $\mathrm{O}$, but there was no consistent evidence of an increase in mortality with increasing category of simple pneumoconiosis. Mortality from all non-violent causes increased systematically with increases in estimates of exposure to dust before the start of the follow up. That gradient was attributable primarily to deaths certified as due to pneumoconiosis and those recorded as due to bronchitis and emphysema $(p<0.001)$. There was some evidence of a dust related increase in deaths from cancers of the digestive system $(p \approx 0.05)$, but none of an association between exposure to coalmine dust and lung cancer. Lung cancer mortality, assessed over 17 year periods, was about 5.5 times higher in smokers than in life long non-smokers. Smokers with no pneumoconiosis had slightly higher lung cancer death rates than smokers with pneumoconiosis. We conclude that miners exposed to excessive amounts of respirable coalmine dust are at increased risk of premature death, either from progressive massive fibrosis or from chronic bronchitis or emphysema.

Does the inhalation of coalmine dust increase the risk of premature death in miners? The question was debated in medical publications a century ago and controversies have continued ever since. The early arguments were based mainly on clinical impressions and inadequate mortality statistics. Some observers were convinced that working conditions in coalmines were not unhealthy, ${ }^{1}$ that the miners had good health and low death rates, ${ }^{2}$ and even that coal dust might be a "preserving element," a "special protective feature in coalmining operations," distinguishing that industry from what were seen as more dangerous metal ore mining operations. ${ }^{3}$ Other authorities were less san-

Received 28 January 1985

Accepted 18 February 1985 guine. Ogle thought that "all things considered, the protective influence of coal dust must be left an open question," 4 and Arlidge doubted that inhalation of coalmine dust could enhance health, reduce disease, and lower death rates. ${ }^{5}$ He agreed that coalminers appeared to have remarkably low general mortality but drew attention to wide regional variations in the data and the high death rates from respiratory diseases. More statistics would be required, he thought, to justify the claim that coalminers had a relatively low mortality.

Those statistics became available in subsequent reports on occupational mortality from the Registrar General. A review in 1948 drew attention to data in four of those decennial reports, those for 1901 to 1931 . They showed that in coalminers aged over 55 the risk 
of death from respiratory diseases other than tuberculosis had been consistently higher than similar risks for all occupied and retired men. ${ }^{6}$ Nevertheless, Fletcher was able to cite, in turn, an author of a text book on occupational diseases, two Milroy lecturers, and one eminent scientist to exemplify what he characterised as "ill-informed complacency" among medical men during the first three decades of the twentieth century about risks to health arising from exposure to coalmine dust. ${ }^{6}$

The Medical Research Council's (MRC) cross sectional health surveys of coalmining communities in the 1950 s provided the basis for later mortality studies. A six year follow up of $97 \%$ of all male residents in one Welsh mining valley was reported in $1964 .{ }^{7}$ The results indicated an approximately $40 \%$ excess mortality among the miners and ex-miners as compared with other men in England and Wales and a much higher risk of death (standardised mortality ratio, SMR = 171) for those with large radiographic shadows indicating massive fibrosis of the lung (progressive massive fibrosis, PMF). But there was little difference in mortality between miners with only small rounded shadows on their radiographs (coalworkers' simple pneumoconiosis) and their contemporaries with no radiological abnormality. A 20 year follow up of the same group broadly confirmed these findings ${ }^{8}$ and showed in addition that men with only the earliest signs of PMF (category A shadows on the International Labour Office's scale) also had a similar life expectation, at least over 20 years, as miners with no pneumoconiosis at all (category 0 on the scale). A later paper ${ }^{9}$ elaborated the analyses and responded to critical comments that had been stimulated by the preliminary report. ${ }^{8}$ The absence of a clear cut difference in mortality between miners with simple pneumoconiosis and those with category 0 was supported by two smaller MRC studies of miners aged 55-64 in Lancashire and Derbyshire, ${ }^{1011}$ by two reports from the United States, ${ }^{1213}$ and by a 14 to 18 year follow up of more than 17000 British coalminers who had worked in 24 collieries selected from all the major coalfields in England, Wales, and Scotland. ${ }^{14}$

We report now on an extension of the latter study to a larger group of men and over a longer follow up period. The data are from the National Coal Board's Pneumoconiosis Field Research (PFR). ${ }^{15}$ An important feature of this material is that the radiological assessments of pneumoconiosis among the miners are supplemented by independent estimates of the men's prior exposures to respirable coalmine dust. This provides a unique opportunity for a direct approach to the question prefacing this paper. Specifically, does exposure to respirable coalmine dust increase mortality risks? And if so to what diseases are the excess deaths attributed?

\section{Material and methods}

STUDY POPULATION

The group being studied numbers 26363 miners from 20 collieries in England and Wales who attended a series of medical surveys between 1953 and 1958.* This constitutes more than $90 \%$ of the miners who were working at those collieries at that time. Their geographical distribution has been documented previously together with details of the wide range of types of coal and the mineral compositions of those coals. ${ }^{1617}$

\section{RADIOLOGICAL DATA}

Full size posterior anterior chest radiographs were made of all the men. The radiological classifications used here were made by at least two doctors working independently within a short period (not more than one year) soon after the surveys. They used the four categories of simple pneumoconiosis defined by the International Labour Office (1953) classification (0, 1 , 2,3 ) and categorised large shadows according to their size $(\mathrm{A}, \mathrm{B}, \mathrm{C}) .^{18}$ Where there was disagreement between the readers' classification, the films were reexamined jointly by the doctors concerned and a "definitive" classification was agreed. ${ }^{15}$

\section{ESTIMATES OF DUST EXPOSURE}

The method used to estimate individual miners exposures to dust before the start of the study was the same as that adopted in the previous mortality follow up, ${ }^{14}$ but it differed in some respects from that described in an earlier report. ${ }^{19} \mathrm{~A}$ detailed occupational history had been taken at interview from each man surveyed. The time worked in the coal industry was classified into six broad categories of coalmining activity. The products of those times (in hours) and estimates of concentrations of respirable dust $\left(\mathrm{g} / \mathrm{m}^{3}\right)$ corresponding to the six categories were summed. The mean dust concentrations had been estimated from systematic dust sampling close to where men were working in the collieries concerned during an approximately 10 year period after the medical surveys. ${ }^{17}$ Such estimates of exposure, from occupational histories judged as reliable by survey interviewers, were available for $19550(74 \%)$ of the men in the study population. (Occupational histories of men who were surveyed only at the first of the series of medical examinations in the PFR were abandoned in the mid-1960s, before the mortality study began.)

*The field research also included four Scottish collieries. The mortality of the $\mathbf{5 2 8 4}$ men surveyed at those mines is not described here because of a known region specific bias in the follow up at the time that the analyses were undertaken. This fault in the data has since been repaired, and results will be reported separately. 
Table 1 Follow up results at 1 August 1980

\begin{tabular}{|c|c|c|c|}
\hline & No & & $\begin{array}{l}\text { Percentages } \\
\text { (rounded) }\end{array}$ \\
\hline $\begin{array}{l}\text { Alive } \\
\text { Dead } \\
\text { Total traced }\end{array}$ & $\begin{array}{r}16247 \\
8489\end{array}$ & 24736 & $\begin{array}{l}62 \\
32\end{array}$ \\
\hline $\begin{array}{l}\text { Believed dead, but no details } \\
\text { available } \\
\text { Not in UK ("embarked") } \\
\text { Not identified by OPCS } \\
\text { Processing of data not } \\
\text { completed at } 1 \text { August } 1980\end{array}$ & $\begin{array}{l}250 \\
963 \\
408\end{array}$ & & $\begin{array}{r}<1 \\
1 \\
4 \\
2\end{array}$ \\
\hline $\begin{array}{l}\text { Total not traced } \\
\text { Total study population }\end{array}$ & & $\begin{array}{r}1627 \\
26363\end{array}$ & $\begin{array}{r}6 \\
100\end{array}$ \\
\hline
\end{tabular}

\section{DETERMINATION OF VITAL STATUS}

Efforts to determine death or survival of the men being studied began in 1970 and they continue. Details identifying individuals were verified and, where necessary, corrected by staff at the Records Branch of the Department of Health and Social Security. The corrected identifications were passed to the Office of Population Censuses and Surveys (OPCS) for searches in the National Health Service Central Registers (NHSCR). Records for men found to be registered in the NHSCR were "flagged" by OPCS staff, and subsequent and earlier deaths were notified to the research team by the provision of copies of death certificates with "underlying cause of death" coded by OPCS staff according to the 7th and 8th revisions of the International Classification of Diseases, Injuries and Causes of Death (ICD), ${ }^{20}$ as appropriate.

METHODS OF ANALYSIS

Preliminary analyses compared the mortality from all causes experienced by the study population up to the end of 1979 with the Registrar General's published annual mortality statistics for the male home population, stratified by age and geographical region. Standardised mortality ratios (SMRs) were calculated by the man-years-at-risk method. ${ }^{21}$

"Life table" methods, widely used in demographic and actuarial applications, ${ }^{22}$ were used to estimate and compare the distributions of survival times for selected subgroups of the study population. Because the radiographic surveys took place in different calendar years, the life tables were formed in units of years of follow up from date of first survey. For analyses of specific causes of death, deaths from other causes were treated, when they occurred, as events that prevented further follow up ("censoring" events). Mortality is expressed here as the estimated percentage survival at 22 years of follow up; this figure may be interpreted as reflecting the hypothetical net probability of surviving that period if the particular cause of death concerned were the only risk present. Provided that the several causes of death which are of interest operate by independent mechanisms, this method permits comparisons to be made for a particular cause across subgroups, regardless of whether these subgroups exhibit differences from other causes. The calculations for the survival estimates and their standard errors were performed by the computer program BMDP1L. ${ }^{23}$

Inferences from the data appeal to a "proportional hazards model." This postulates that the ratio of any risks of death that are being compared is constant over time. The appropriate parameters of such models were estimated by standard procedures ${ }^{24}$ using the calculated cumulative survival rates.

Table 2 Regionally standardised mortality ratios by colliery

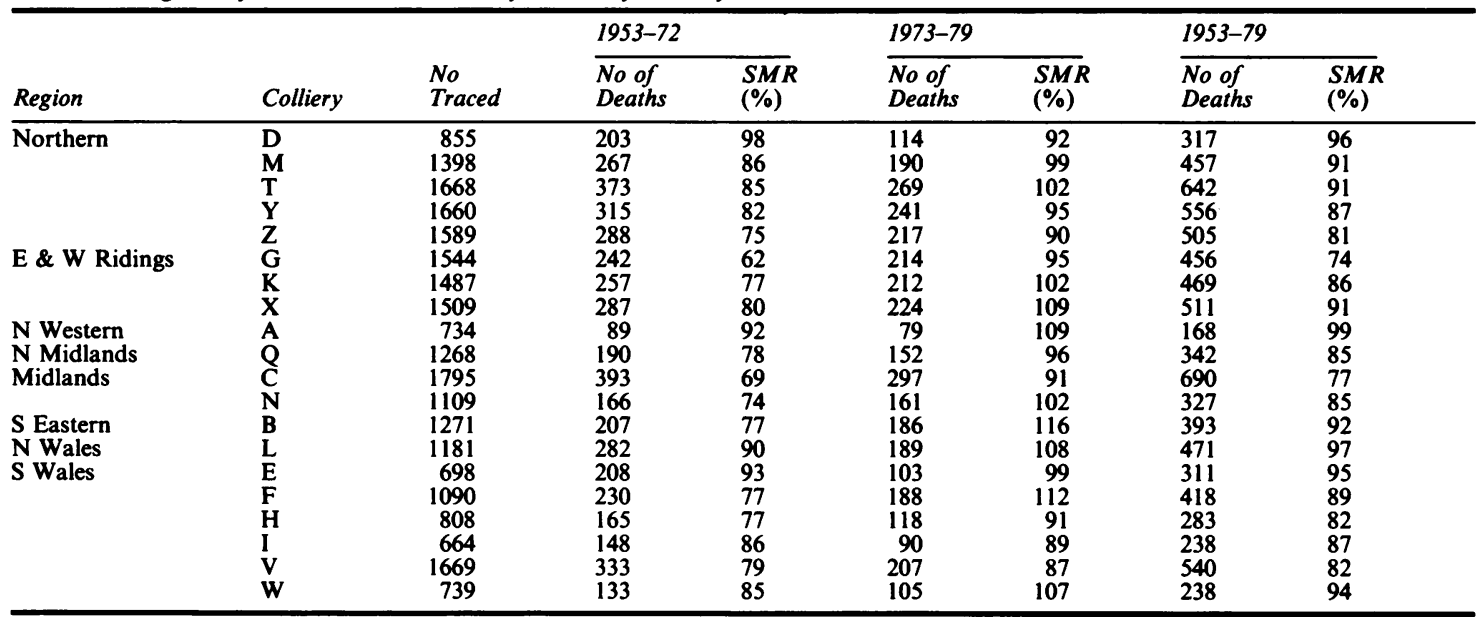


Table 3 Distribution of all traced miners by age and radiological classification at first survey

\begin{tabular}{|c|c|c|c|c|c|c|c|c|}
\hline \multirow{2}{*}{ Radiological category } & & \multicolumn{6}{|c|}{ Age at first survey } & \multirow[b]{2}{*}{ Total } \\
\hline & & $<25$ & $25-34$ & $35-44$ & $45-54$ & $55-64$ & $\geqslant 65$ & \\
\hline $\begin{array}{l}\text { No signs } \\
\text { Simple pneumoconiosis } \\
\text { PMF } \\
\text { Total }\end{array}$ & $\begin{array}{r}\mathbf{0} \\
\mathbf{1} \\
2 \\
3 \\
\mathbf{A} \\
\mathbf{B} \\
\mathbf{C}\end{array}$ & $\begin{array}{r}4267 \\
3 \\
0 \\
0 \\
0 \\
1 \\
0 \\
4271\end{array}$ & $\begin{array}{r}5009 \\
160 \\
48 \\
5 \\
10 \\
3 \\
0 \\
5235\end{array}$ & $\begin{array}{r}4905 \\
457 \\
199 \\
28 \\
93 \\
23 \\
6 \\
5711\end{array}$ & $\begin{array}{r}4502 \\
615 \\
304 \\
47 \\
133 \\
82 \\
18 \\
5701\end{array}$ & $\begin{array}{r}2450 \\
445 \\
170 \\
34 \\
106 \\
84 \\
25 \\
3314\end{array}$ & $\begin{array}{r}382 \\
59 \\
26 \\
4 \\
19 \\
10 \\
4 \\
504\end{array}$ & $\begin{array}{r}21515 \\
1739 \\
747 \\
118 \\
361 \\
203 \\
53 \\
24736\end{array}$ \\
\hline
\end{tabular}

\section{Results}

\section{TRACING RATES}

When the analyses reported here began, vital status had been determined successfully for $94 \%$ of the miners in the study population. Table 1 shows details of why the other (1627) men were not considered further at that stage. Nearly $60 \%$ were not unambiguously identifiable on the NHSCR, given the information available, and another $15 \%$ had left the United Kingdom at the time when searches were made, so that their vital status in 1980 could not be confirmed. Information about the remainder was not yet secure, mainly because searches by the OPCS were still in progress.

Research records referring to the $6 \%$ untraced were examined with a view to assessing the degree to which their omission from the analyses may have influenced the results. Forty per cent (659 men) did not attend any of the subsequent PFR medical surveys that took place at the same mines at roughly five year intervals. In some cases this will have been due to normal retirement, but more than two thirds of this subgroup (450 men) were aged under 60 at the time of survey.

The subgroup of 250 men who had left the United Kingdom were younger on average than those traced, only 31 being over 45 at survey. Those "embarked" included some from each of the 20 collieries and, allowing for age, the distribution of pneumoconiosis in this subgroup did not differ from that in those traced.
On the other hand, although each of the 20 collieries contributed some men to the total of 1627 declared untraced, there were disproportionately more older men among them, and more with pneumoconiosis, than in those traced. This implies that the available data are not truly representative of the particular group of miners who were surveyed with respect to age and prevalence of pneumoconiosis. Our results may therefore slightly understate the true mortality in the whole study population.

The main emphasis of what follows, however, is on internal comparisons between subgroups of those traced. The fact that those untraced span all the age groups considered, and also all categories of pneumoconiosis, makes it unlikely that their omission from the analysis will have seriously distorted the mortality contrasts within the whole population, particularly since those comparisons are made within age groups.

COMPARISONS WITH MORTALITY IN ALL MEN, ENGLAND AND WALES

Table 2 shows the regional and age standardised mortality ratios for each of the 20 collieries over the maximum possible follow up periods. (These varied from 22 to 26 years, depending on when, in the period 1953-8, the initial medical surveys took place.) Summary statistics, based on the same data, but calculated separately for the first 20 and last six calendar years of the study are also shown. Attention is drawn to three features of these results. (1) All 20 SMRs referring to the maximum possible follow up periods are less than

Table 4 Estimated percentage survival at 22 years (with standard error) from all non-violent causes of death, by age and radiological classification at first survey

\begin{tabular}{|c|c|c|c|c|c|}
\hline \multirow{2}{*}{ Radiological category } & & \multicolumn{4}{|c|}{ Age at first survey } \\
\hline & & $25-34$ & $35-44$ & $45-54$ & $55-64$ \\
\hline $\begin{array}{l}\text { No signs } \\
\text { Simple pneumoconiosis }\end{array}$ & $\begin{array}{r}\mathbf{0} \\
\mathbf{1} \\
\mathbf{2} \\
\mathbf{3} \\
\mathbf{A} \\
\mathbf{B} \\
\mathbf{C}\end{array}$ & $\begin{array}{l}93 \cdot 8(0 \cdot 3) \\
90 \cdot 6(2 \cdot 3) \\
91 \cdot 7(4 \cdot 0) \\
60 \cdot 0(21 \cdot 9) \\
80.0(12 \cdot 6) \\
33 \cdot 3(27 \cdot 2) \\
-*\end{array}$ & $\begin{array}{l}82.8(0.5) \\
80.9(1.8) \\
80.4(2.8) \\
96.3(3.6) \\
72.0(4 \cdot 6) \\
73.9(9 \cdot 2) \\
33.3(19 \cdot 2)\end{array}$ & $\begin{array}{l}58 \cdot 2(0 \cdot 7) \\
56 \cdot 6(2 \cdot 0) \\
60 \cdot 4(2 \cdot 8) \\
55 \cdot 3(7 \cdot 3) \\
51 \cdot 9(4 \cdot 3) \\
36 \cdot 6(5 \cdot 3) \\
11 \cdot 1(7 \cdot 4)\end{array}$ & $\begin{array}{r}27 \cdot 4(0.9) \\
23.6(2 \cdot 0) \\
26 \cdot 5(3 \cdot 4) \\
21 \cdot 3(7 \cdot 1) \\
20 \cdot 3(3 \cdot 9) \\
17 \cdot 1(4 \cdot 2) \\
4 \cdot 3(4 \cdot 2)\end{array}$ \\
\hline
\end{tabular}

*No data 
100 , showing that mortality in these groups of coalminers was certainly no worse, and in some cases distinctly better, than that of their contemporaries among English and Welsh men generally. (2) In all but one case (colliery D) the SMR during the latter six year period was higher than that for the first 20 years, in some cases exceeding 100 marginally in the later years. (3) These regionally adjusted colliery specific SMRs show variations within regions that are unlikely to be due to chance alone.

The purpose of the analyses that follow is to try to explain some of the variability in the data in terms of radiological categories and exposures to dust.

\section{MORTALITY AND RADIOLOGICAL CATEGORY}

Table 3 shows the age and pneumoconiosis category distribution in the 24736 men who were traced. This arrangement defines the numbers of men initially at risk of death and provides the basis for the comparisons elaborated in table 4 . The data in table 3 show the expected association between increasing age and severity of pneumoconiosis although there were a few younger men, aged under 35 , with more advanced radiological abnormalities.

The mortality experienced within the risk sets defined by table 3 for all non-violent causes (ICD codes 000-799) is summarised in table 4. (Men under 25 and those over 64 are omitted; the small numbers available imply that estimates are imprecise or not calculable.) The figures presented for each risk set are the estimated cumulative percentage survival at 22 years of follow up, and the corresponding estimated standard error.

It is clear that in each age group men with PMF, including those with " $A$ " shadows, had considerably poorer survival prospects than other miners. The results imply that relative risks of death for men with category $\mathbf{A}$, compared with those with category 0 , were about $3.5,1.7,1.2$, and 1.2 respectively in the four increasing age groups between 25 and 64 .

Some decrease in survival rates is evident also in almost all of the subgroups with simple pneumoconiosis. This is particularly noticeable in those with category 1 , who constituted the bulk of those with simple pneumoconiosis, and whose survival rates were consistently lower than those of men without radiological abnormality.

Similar analyses were performed for several causes and groups of causes of death.* The main features of these results may be summarised as follows. As expected, mortality ascribed to pneumoconiosis showed a clear pattern of increase with increasing

\footnotetext{
* These and other detailed results, not shown here, are described in an Institute of Occupational Medicine report, TM/81/10. This also provides further information about the follow up and statistical methods.
}

initial category of severity. Results for cancers of the digestive system and for bronchitis and emphysema suggested slightly increased mortality from these causes among men with pneumoconiosis, but the trends were not strong.

No associations were found between radiological category and mortality ascribed to ischaemic heart disease or to lung cancer. The latter result was based on an analysis, unadjusted for possible variations in smoking habits, of 550 deaths from lung cancer over 22 years. They represented $8.3 \%$ of all non-violent deaths during that period.

Just over two thirds of those traced (16954 men) survived to attend further surveys at the collieries, about five years after the initial surveys. On that occasion the miners were asked about their smoking habits. ${ }^{19}$ Subsequent survival in this smaller group, over shorter (17 year) periods, was studied separately with respect to smoking habits and radiological category as determined at the second surveys. Analysis of 315 deaths from lung cancer in those aged between 35 and 64 who were smokers at that time $(76 \%$ of those in that age group) was based on a proportional hazards model. The results suggested that lung cancer hazards for men with simple pneumoconiosis and for those with PMF were $18 \%$ and $26 \%$ lower respectively than the corresponding (age adjusted) risks for men whose radiographs had been classified as category 0 . The negative lung cancer gradient with increasing severity of pneumoconiosis among smokers was significant at about the $12 \%$ level $\left(\chi^{2}=2.40\right.$ from a log-likelihood test with one degree of freedom).

There were only 10 deaths from lung cancer during those 17 years among the 2373 non-smokers (all occurring in 2019 men with category 0 ) and 16 among 1252 miners who declared themselves to be exsmokers. Differences between smoking categories (again under a proportional hazards model, adjusting for age but ignoring radiological category) were highly significant. The lung cancer hazard for smokers was estimated to be 5.5 times that for non-smokers and 2.3 times that for ex-smokers.

\section{MORTALITY AND DUST EXPOSURE}

Table 5 shows the distribution of 19550 men for whom exposure estimates were available, stratified by 10 year age groups and ranges of estimated cumulative dust exposure up to the first survey. Whereas it is obvious that the younger men generally have lower exposures, there is sufficient spread within each age range to allow exposure specific comparisons to be made.

Estimates of survival at 22 years from all nonviolent causes within the risk sets contained in table 5 appear in table 6 . There is a clear trend of decreasing survival with increasing exposure to respirable mine 
Table 5 Distribution of traced miners with employment histories by age and estimated cumulative exposure to respirable mine dust up to first survey

\begin{tabular}{|c|c|c|c|c|c|c|c|}
\hline \multirow{2}{*}{$\begin{array}{l}\text { Estimated dust exposure } \\
\left(\mathrm{gh} / \mathrm{m}^{3}\right)^{*}\end{array}$} & \multicolumn{7}{|c|}{ Age at first survey } \\
\hline & $<25$ & $25-34$ & $35-44$ & $45-54$ & $55-64$ & $\geqslant 65$ & Total \\
\hline $\begin{array}{c}0-30 \\
30-90 \\
90-180 \\
>180\end{array}$ & $\begin{array}{r}2527 \\
501 \\
35 \\
0 \\
3063\end{array}$ & $\begin{array}{r}1179 \\
1850 \\
1162 \\
222 \\
4413\end{array}$ & $\begin{array}{r}694 \\
1409 \\
1750 \\
1172 \\
5025\end{array}$ & $\begin{array}{r}302 \\
864 \\
1512 \\
2311 \\
4989\end{array}$ & $\begin{array}{r}82 \\
241 \\
516 \\
1081 \\
1920\end{array}$ & $\begin{array}{r}8 \\
17 \\
32 \\
83 \\
140\end{array}$ & $\begin{array}{r}4792 \\
4882 \\
5007 \\
4869 \\
19550\end{array}$ \\
\hline
\end{tabular}

*The exposure units are products of working time and respirable dust concentrations, expressed as gram-hours per cubic metre of sampled air.

Table 6 Estimated percentage survival at 22 years (with standard error) from all non-violent causes, by age and estimated dust exposure up to first survey

\begin{tabular}{lllll}
\hline Estimated dust exposure $\left(\mathrm{gh} / \mathrm{m}^{3}\right)$ & \multicolumn{4}{l}{ Age at first survey } \\
\cline { 2 - 5 } & $25-34$ & $35-44$ & $45-54$ & $55-64$ \\
\hline $0-30$ & $94 \cdot 0(0 \cdot 7)$ & $84 \cdot 8(1 \cdot 4)$ & $68 \cdot 1(2 \cdot 7)$ & $57 \cdot 2(5 \cdot 6)$ \\
$30-90$ & $94 \cdot 3(0 \cdot 5)$ & $84 \cdot 1(1 \cdot 0)$ & $61 \cdot 4(1 \cdot 7)$ & $31 \cdot 9(3 \cdot 0)$ \\
$90-180$ & $92 \cdot 1(0 \cdot 8)$ & $84 \cdot 1(0 \cdot 9)$ & $60 \cdot 2(1 \cdot 3)$ & $36 \cdot 6(2 \cdot 1)$ \\
$>180$ & $92 \cdot 7(1 \cdot 8)$ & $80 \cdot 7(1 \cdot 2)$ & $58 \cdot 4(1 \cdot 0)$ & $29 \cdot 9(1 \cdot 4)$ \\
\hline
\end{tabular}

Table 7 Estimated percentage survival at 22 years (with standard error) from bronchitis and emphysema, by age and estimated dust exposure up to first survey

\begin{tabular}{lllll}
\hline Estimated dust exposure $\left(\mathrm{gh} / \mathrm{m}^{3}\right)$ & \multicolumn{5}{l}{ Age at first survey } & & $55-64$ \\
\cline { 2 - 5 } & $25-34$ & $35-44$ & $45-54$ & $97 \cdot 0(2 \cdot 1)$ \\
\hline $0-30$ & $99 \cdot 9(0 \cdot 1)$ & $99 \cdot 4(0 \cdot 3)$ & $97 \cdot 0(1 \cdot 1)$ & $97 \cdot 9(2 \cdot 9)$ \\
$30-90$ & $99 \cdot 8(0 \cdot 1)$ & $99 \cdot 1(0 \cdot 3)$ & $94 \cdot 2(0 \cdot 9)$ & $90 \cdot 1(1 \cdot 7)$ \\
$90-180$ & $99 \cdot 6(0 \cdot 2)$ & $98 \cdot 8(0 \cdot 3)$ & $94 \cdot 4(0 \cdot 7)$ & $82 \cdot 8(1 \cdot 6)$ \\
$>180$ & $99 \cdot 1(0 \cdot 6)$ & $97 \cdot 3(0 \cdot 5)$ & $93 \cdot 8(0 \cdot 6)$ & \\
\hline
\end{tabular}

Table 8 Estimated percentage survival at 22 years (with standard error) from cancers of the digestive organs and peritoneum, by age and estimated dust exposure up to first survey

\begin{tabular}{lllll}
\hline Estimated dust exposure $\left(\mathrm{gh} / \mathrm{m}^{3}\right)$ & \multicolumn{5}{l}{ Age at first survey } & & $55-64$ \\
\cline { 2 - 5 } & $25-34$ & $35-44$ & $97 \cdot 1(1 \cdot 0)$ & $94 \cdot 6(3 \cdot 1)$ \\
\hline $0-30$ & $99 \cdot 3(0 \cdot 2)$ & $98 \cdot 6(0 \cdot 5)$ & $95 \cdot 6(0 \cdot 8)$ & $93 \cdot 5(2 \cdot 1)$ \\
$30-90$ & $99 \cdot 0(0 \cdot 2)$ & $98 \cdot 6(0 \cdot 3)$ & $96 \cdot 1(0 \cdot 6)$ & $94 \cdot 5(1 \cdot 3)$ \\
$90-180$ & $98 \cdot 8(0 \cdot 3)$ & $98 \cdot 2(0 \cdot 3)$ & $94 \cdot 8(0 \cdot 5)$ & $91 \cdot 4(1 \cdot 1)$ \\
$>180$ & $100 \cdot 0(0 \cdot 0)$ & $98 \cdot 4(0 \cdot 4)$ & 9 \\
\hline
\end{tabular}

dust, despite some sampling fluctuations. This suggests that exposure to mine dust is associated with increased mortality hazard, for some causes of death at least.

A similar analysis (not reproduced here) of deaths attributed to pneumoconiosis displayed, as expected, a strong relation with dust exposure. Of 164 deaths certificated as having pneumoconiosis as the underlying cause, only five were from men having initial exposure estimates less than $90 \mathrm{gh} / \mathrm{m}^{3}$, and most were from men with values over $180 \mathrm{gh} / \mathrm{m}^{3}$.

Table 7 gives survival estimates in the same risk sets from deaths attributed to bronchitis or emphysema or both (ICD 500-502 (7th rev), 490-492 (8th rev)). Analysis of the results in this table under a proportional hazards model indicated that, allowing for age, there was an asssociation, statistically significant at better than the $0.1 \%$ level, between increasing exposure and increasing hazard of death from bronchitis and emphysema.

Table 8 shows the survival estimates for deaths from cancers of the digestive organs (ICD 150-159). There are only trivial differences between exposure groups in the younger men, but the figures for those aged between 45 and 64 at the start of follow up suggest a possible trend, similar to that found in the younger men: those with high dust exposures had higher mortality certified as due to these diseases. A formal test of the null hypothesis of no association between digestive cancer mortality and exposure to dust, using all the data in table 8, yielded a test statistic just significant at the $5 \%$ level $\left(\chi_{1}^{2}=4 \cdot 07\right)$. Thus there appears to be some evidence from these results supporting the idea of a link between exposure to coalmine dust and cancers of the digestive system.

Survival estimates for ischaemic heart disease and 
for lung cancer were similar across exposure groups and showed no obvious patterns of association with exposure to dust.

\section{Discussion}

\section{BIASES}

The main potential sources of bias in the results reported above are the higher average age and more prevalent pneumoconiosis in the $6 \%$ not traced, and the non-availability of dust exposure estimates for $19 \%$ of those who were traced. (The latter group, too, was older on average, and included a higher proportion of men with pneumoconiosis than the study group as a whole.) Mortality comparisons with the general male population, using regional and age standardised mortality ratios, may have understated the true situation slightly because of the incomplete follow up.

We were not suprised by the generally favourable mortality in this group of miners relative to that in all men. As long ago as 1885 Ogle identified one good reason why this should be so: “... miners are a body of picked men. No very weakly man is likely to take to the occupation; and ... many who become weakly have to abandon this form of labour for lighter work." 4 The cross sectional sample of working miners constituting our study group included $38 \%$ aged 55 or over at the outset. Their mortality over the ensuing 22 years was probably less severe than the average for all men, since the latter include the chronically sick and disabled. Fox and Collier have drawn attention to the fact that the importance of this selection effect is likely to diminish as follow up proceeds in a longitudinal study. ${ }^{25}$ Our results, showing an increase in colliery specific SMRs during the last six years of the study, are consistent with that prediction. These and other population selection factors complicate the interpretation of SMRs as indices of relative risks in mortality studies aimed at quantifying the importance of the occupational environment, particularly since the extent to which they influence results may vary for different causes of death. ${ }^{26}$ This was why we concentrated attention on age specific comparisons between survival rates within the group studied, with respect to initial radiographic categories and estimates of the miners' exposures to dust up to start of follow up.

Probably the generally older miners for whom we had no occupational histories had experienced exposures to dust that were mainly in the upper part of the range described. It is possible, though less likely, that their responses to those higher exposures differed systematically from those that we were able to analyse. To that extent our assessments of associations with dust exposure could be biased.

Three findings are of particular interest.
MORTALITY AND RADIOLOGICAL CATEGORY Firstly, the survival rates over 22 years for miners with early PMF shadows (category A) are substantially and significantly lower than in men with no pneumoconiosis initially. This is not a surprising result, bearing in mind the well established high fatality rate for men with categories $B$ and $C^{7-9}$ and the progressive nature of the disease. ${ }^{27}$ Nevertheless, we draw attention to the finding because our earlier analysis of part of this material, over shorter follow up periods, failed to identify clearly increased mortality in men with " $A$ " shadows initially ${ }^{14}$; and also because a similar observation in the 20 year Rhondda Fach follow up ${ }^{89}$ led Cochrane to postulate a complex "selection" theory to explain the absence of an effect.

One idea was that miners with low "risk factors" for ischaemic heart disease might be particularly susceptible to $\mathrm{PMF}^{28}$; but no biological model was suggested to explain such a mechanism. In the light of the results presented now such speculations appear to be unnecessary. With 22 years follow up, the earlier impression of little excess mortality in all those with " $A$ " shadows is removed. (Even our earlier results, ${ }^{14}$ and those from the Rhondda, ${ }^{8}$ showed lower survival rates for men with " $A$ " shadows who were 55 or over at start of follow up.) Moreover, we have found no association, positive or negative, between mortality attributed to ischaemic heart disease and initial category of complicated (or simple) pneumoconiosis.

The second result worthy of comment is that there are reductions in survival rates over 22 years in most subgroups with simple pneumoconiosis initially. Again, this effect was much less apparent over shorter follow up periods and, again, those earlier results ${ }^{14}$ were similar to those found, after 20 years, in the Rhondda survey. ${ }^{89}$ Indeed, the similarity between results from the two studies at that time was remarkable in this respect, including concordant indications that some subgroups of miners who had developed simple pneumoconiosis at an early age (under 45 at start of follow up) did have poorer survival prospects than miners with no pneumoconiosis. In both studies, however, the averages of results over all age groups did not support the idea that simple pneumoconiosis was associated with higher mortality ${ }^{914}$; nor was there any sign of a trend for mortality to increase with increasing profusion of small shadows, from categories 1 to 3 .

The slightly reduced survival rates among men with simple pneumoconiosis shown now in our data, with a longer follow up, are more consistent with what might be expected from the higher mortality in men with PMF and the increasing risk of developing PMF with increasing category of simple pneumoconiosis. ${ }^{2930}$ Yet the absence of any tendency for mortality to increase with increasing category of sim- 
ple pneumoconiosis remains conspicuous. We do not interpret the lack of such a gradient as necessarily conflicting with a suggestion that in the long run coalminers with simple pneumoconiosis may be expected to have lower probabilities of survival than similarly aged colleagues with no radiological signs. Our reasoning is as follows.

With further exposure to dust, some of those whose radiographs were classified as category 1 at the outset will have developed category 2 or 3 (or even PMF) within the 22 year observation period that we considered. Similarly, there will have been a non-trivial incidence of simple pneumoconiosis from category 0 during the same period. This is true in all prospective studies of coalminers' mortality, and it is bound to obscure contrasts based on initial categories of pneumoconiosis.

Many of the miners included in the present study were examined again at subsequent radiological surveys; and we have those results. In principle, therefore, it is possible to take into consideration temporal changes in radiological status as the follow up proceeded, at least in some subgroups. Formidable statistical and computing problems are implicit in an analysis along these lines, but recent developments in both these areas suggest that those problems are not insuperable. We hope to report further on this aspect of our data.

\section{MORTALITY AND DUST EXPOSURE}

The third major result to which we want to draw attention is the tendency for men with higher exposures to dust at the outset, particularly those in the two older age groups, to have reduced survival rates from all non-violent causes. Note that one consequence of the reduced survival rates for men with pneumoconiosis, recorded above, is as follows: if there is a bias in the results with respect to dust exposure because of the non-availability of occupational histories for some men, then that bias is more likely to be in the direction of underestimating, rather than of overestimating, the gradients with dust exposure.

It is a fact, however, that the exposures we have calculated are but approximations to the exposures that were actually experienced. The estimates were derived partly from information obtained at interviews, which is subject to errors arising from lapses of memory, particularly among the older men. Moreover, the conversion of these historical records into exposure units is based on an unverifiable assumption about the approximate equivalence of mean dust concentrations measured during the first 10 years of follow up to mean concentrations at similar workplaces before the medical surveys.

Yet the exposure related gradient for all non-violent causes is more obvious in these data than that indi- cated by category of simple pneumoconiosis. This reinforces our opinion that the quantitative estimates of exposure that we have used here are more realistic reflections of the miners' actual exposures to respirable dust up to start of follow up than the radiological classifications at that time. That view is founded on more general grounds. Although there is a clear quantitative relation between cumulative exposures to respirable coalmine dust and risks of developing pneumoconiosis, the relation is essentially probabilistic, not deterministic. Most miners who are exposed even to fairly high levels of dust do not develop radiological signs. For instance, one study shows that fewer than $7 \%$ of 1018 miners, who had all been exposed to $200 \mathrm{gh} / \mathrm{m}^{3}$ dust or more over periods exceeding 20 years, showed signs amounting to category 2 simple pneumoconiosis at the end of those periods. ${ }^{31}$ In the present study some $13 \%$ of the miners who were traced had pneumoconiosis (category 1 or higher) at the outset. But our estimates of exposure to dust for $80 \%$ of those traced suggest that at least a quarter had experienced exposures exceeding 180 $\mathrm{gh} / \mathrm{m}^{3}$; and in that higher exposure range 3101 men $(64 \%)$ had radiographs classified as category 0 .

\section{CA USES OF DEATH}

The analyses confirmed that, as expected, an important element in the relation between exposure to dust and mortality from all non-violent causes was a strong association between the exposures and deathe certified as due to pneumoconiosis. Nevertheless, there was also an unambiguous and highly significant trend for higher exposures to be associated with higher risks of death in other men, where bronchitis and emphysema were nominated as the underlying causes.

It is well recognised that the primary cause of death as recorded on the death certificate is not necessarily an accurate statement of the real cause of death. ${ }^{32-34}$ Clearly, this source of error makes it difficult to interpret "cause specific" mortality data that are based solely on death certifications. ${ }^{1435}$ Nevertheless, we think that the difficulty is reduced when considering contrasts within this particular group of miners. Whatever errors there may be in the certifications, there is no reason to suppose that they should occur more or less often in one or other subgroup defined according to an index of dust exposure that has been derived independently of radiological or necropsy appearances. If that assumption is valid then it is reasonable to conclude that high exposures to coalmine dust were related to deaths from bronchitis and emphysema $(\mathrm{p}<0.001)$.

Support for the idea that the exposure related deaths attributed to bronchitis and emphysema reflect pathology characteristic of those respiratory condi- 
tions (rather than just nosological artefacts or certifying doctors' prejudices) comes from studies of other material generated by the same project. Measured exposures to dust have been related both to reductions in levels of age standardised lung function assessed cross sectionally ${ }^{3637}$ and to an acceleration of the decline in function with age. ${ }^{38}$ Symptoms of chronic bronchitis have also been related to dust exposures in young miners. ${ }^{19}$ Additional support comes from postmortem studies which show that in miners whose lungs exhibit one or more palpable lesions measuring at least $1 \mathrm{~mm}$ in diameter there is a direct relation between their exposures to dust in life and the probability of having pathologically diagnosable centriacinar emphysema post mortem. ${ }^{39}$

The other group of certified causes of death which the data suggest may be related to dust exposure is that embracing cancers of the digestive system. Most of these (274 of the 318 observed over the 22 year period) were cancers of the stomach. The evidence pointing to an association with dust is not as convincing here as it is for bronchitis and emphysema; but it is consistent with several reports of excess stomach cancer in coalminers ${ }^{40-44}$ and it was found also in our earlier follow up. ${ }^{14}$ The weak association that we find now between the occurrence of these cancers and initial radiological category might reflect an underlying effect of ingested coalmine dust; or it may indicate a more complex carcinogenic mechanism associated with dust induced lung damage; or indeed it may be a statistical artefact, perhaps connected with covariation between the geographical distribution of these cancers in England and Wales, past levels of dust in the different coalfields, and the corresponding prevalences of pneumoconiosis. Our analysis to date of this material is not able to distinguish effectively between these different hypotheses, but the findings are sufficiently suggestive to merit further research.

There have been conflicting reports about lung cancer in coalminers. Some results could be interpreted as indicating that the risk may be lower in coalminers than in the general population. ${ }^{45-48}$ This has led to speculation that either the presence of pneumoconiosis or exposure to coalmine dust might protect miners from lung cancer to some extent. Other studies show no association, ${ }^{94950}$ or record equivocal findings ${ }^{4351-53}$ that some have interpreted as pointing in the opposite direction.

The confused picture is probably due partly to varitions in smoking habits between the various groups considered. For instance, the most recent report on occupational mortality in England and Wales records relatively high death rates for lung cancer in miners and quarrymen in $1970-2(\mathrm{SMR}=116) .{ }^{54}$ But on its own this does not implicate occupational factors, since the same report shows also that there was a relatively high proportion of smokers in that occupation order.

Our results now, and those from earlier analyses of part of this material, ${ }^{55}$ show that neither the study group as a whole, nor those with pneumoconiosis, were immune to the lung cancer hazard associated with smoking. A trend suggesting that among the smokers, risks of lung cancer were lower in those with pneumoconiosis than in those without was not convincing $(p=0 \cdot 12)$. Our lack of conviction on this point is based partly on the difficulty of interpreting death registration data as evidence of real cause of death. It is reinforced by the fact that the analysis with respect to estimates of dust exposure showed no pattern that could be interpreted as indicating either a protective or a potentiating effect of exposure to coalmine dust. It would be unwise, however, to generalise from this observation of no association to coalmine dusts with mineral compositions different from those found in Britain, since several reports indicate that workers exposed to respirable dusts containing high proportions of silica may be at an increased risk from lung cancer. ${ }^{56-58}$ (The quartz contents of respirable dusts to which miners were exposed in the collieries considered here were generally low.) ${ }^{17}$

\section{Conclusion}

We believe that, in the light of all the information available now, the answer to the question "Does the inhalation of coalmine dust increase risks of premature death?" must be "yes." The additional risk certainly occurs if miners have been exposed to levels of dust sufficiently severe to cause massive fibrosis of the lung identifiable radiologically as category $\mathbf{A}$ or higher on the ILO's scale. It occurs also when such exposures have not resulted in massive fibrosis, or perhaps even in the absence of the small radiographic shadows characteristic of coalworkers' simple pneumoconiosis, if the dust exposures are sufficient to cause or enhance lung damage recognised by certifying doctors as chronic bronchitis and emphysema.

It should be recalled, however, that the starting point for the mortality follow up that we have reported is a group of miners who were all active in the industry at least a quarter of a century ago. Dust conditions underground then were very different from what they are now and, as a result, the incidence of pneumoconiosis has certainly been reduced substantially, particularly during the past 15 years. ${ }^{59}$ But the results presented here, and the conclusions that they suggest, re-emphasise the importance of the Coal Board's warnings against complacency: “... it is essential that effective techniques of dust suppression continue to be applied if ground, laboriously and expensively gained, is not to be lost."60 
This work was carried out with financial aid from the European Coal and Steel Community and the National Coal Board. The PFR medical surveys in the 1950 s, and the earlier follow up, were financed wholly by the NCB. One of us (MJ) is particularly grateful to the Board for the opportunity to use that material in earlier work. ${ }^{14}$ Both of us want to thank staff at the Department of Health and Social Security and the Office of Population Censuses and Surveys for making the follow up possible, and also our many colleagues, past and present, who contributed to the clerical, programming, data maintenance, and statistical work over the years.

\section{References}

${ }^{1}$ Greenhow EH. On the different prevalence of certain diseases in different districts of England and Wales. In: General Board of Health. Papers relating to the sanitary state of the people of England. London: HMSO, 1858.

${ }^{2}$ Nasmyth TG. Report on the air of coal mines. $\mathrm{Br} \mathrm{Med} J$ 1888;ii:222-9.

${ }^{3}$ Smart A. Note on anthracocis. Br Med J 1885;ii:439.

${ }^{4}$ Ogle W. Letter to the Registrar General on the mortality in the registration districts of England and Wales during the ten years 1871-80. 45th Annual report of the Registrar General of births, deaths and marriages in England. (Supplement.) London: HMSO, 1885.

${ }^{5}$ Arlidge JT. The hygiene, diseases and mortality of occupations. London: Percival, 1892.

${ }^{6}$ Fletcher CM. Pneumoconiosis of coal-miners. $\mathrm{Br}$ Med J 1948;i:1015-22, 1065-74.

' Cochrane AL, Carpenter RG, Moore F, Thomas J. The mortality of miners and ex-miners in the Rhondda Fach. Br J Ind Med 1964;21:38-45.

${ }^{8}$ Cochrane AL. Relation between radiographic categories of coalworkers' pneumoconiosis and expectation of life. $\mathrm{Br}$ Med J 1973;ii:532-4.

${ }^{9}$ Cochrane AL, Haley TJL, Moore F, Hole D. The mortality of men in the Rhondda Fach, 1950-70. Br J Ind Med 1979;36:15-22.

${ }^{10}$ Cochrane AL, Moore F. Preliminary results of a twenty-year follow-up of a random sample of an industrial town. $\mathrm{Br}$ Med J 1978;i:411-2.

${ }^{11}$ Cochrane AL, Moore F. A 20-year follow-up of men aged 55-64 including coal-miners and foundry workers in Staveley, Derbyshire. Br J Ind Med 1980;37:226-9.

${ }^{12}$ Ortmeyer CE, Baier EJ, Crawford GM. Life expectancy of Pennsylvania coal miners compensated for disability. Arch Environ Health 1973;27:227-30.

${ }^{13}$ Ortmeyer CE, Costello J, Morgan WKC, Swecker S, Peterson M. The mortality of Appalachian coal miners, 1963 to 1971. Arch Environ Health 1974;29:67-72.

14 Jacobsen M. Dust exposure, lung diseases and coalminers' mortality. Edinburgh: University of Edinburgh, 1976. (PhD thesis.)

${ }^{15}$ Fay JWJ, Rae S. The pneumoconiosis field research of the National Coal Board. Ann Occup Hyg 1959;1:149-61.

${ }^{16}$ Rogan JM, Rae S, Walton WH. The National Coal Board's pneumoconiosis field research-an interim review. In: Davis $\mathrm{CN}$, ed. Inhaled particles II. Oxford: Pergamon, 1967:493-508.

${ }^{17}$ Dodgson J, Hadden GG, Jones CO, Walton WH. Characteristics of the airborne dust in British coal mines. In: Walton WH, ed. Inhaled particles III. Old Woking: Unwin Bros, 1971:757-81.

${ }^{18}$ Proceedings of the Third International Conference of Experts on Pneumoconiosis, Sydney, 1950. Vol 1. Geneva: International Labour Office, 1953.

${ }^{19}$ Rae S, Walker DD, Attfield MD. Chronic bronchitis and dust exposure in British coalminers. In: Walton WH, ed. Inhaled particles III. Old Woking: Unwin Bros, 1971:897-900.

${ }^{20}$ Manual of the international statistical classification of disease, injuries and causes of death. Vols 1 and 2. Geneva: World Health Organisation, 1957, 1969.

${ }^{21}$ Hill ID. Computing man years at risk. $\mathrm{Br} J$ Prev Soc $\mathrm{Med}$ 1972;26:132-4.

${ }^{22}$ Gross AJ, Clark VA. Survival distributions: reliability applications in the biomedical sciences. New York: Wiley, 1975.

${ }^{23}$ Dixon WJ, ed. BMDP-79: Biomedical computer programs: P-series. Berkeley: University of California Press, 1979.

${ }^{24}$ Kalbfleisch JD, Prentice RL. The statistical analysis of failure time data. New York: Wiley, 1980.

${ }^{25}$ Fox AJ, Collier PF. Low mortality rates in industrial cohort studies due to selection for work and survival in the industry. $\mathrm{Br} J$ Prev Soc Med 1976;30:225-30.

${ }^{26}$ Enterline PE. What do we expect from an occupational cohort? Not uniformly true for each cause of disease. $J$ Occup Med 1975;17:127-8.

${ }^{27}$ Cochrane AL, Moore F, Thomas J. The radiographic progression of progressive massive fibrosis. Tubercle 1961;42:72-7.

${ }^{28}$ Cochrane AL, Moore F, Moncrieff CB. Are coalminers, with low "risk factors" for ischaemic heart disease at greater risk of developing progressive massive fibrosis? Br J Ind Med 1982;39:265-8.

${ }^{29} \mathrm{Cochrane} \mathrm{AL}$. The attack rate of progressive massive fibrosis. $\mathrm{Br}$ $J$ Ind Med 1962;19:52-64.

${ }^{30}$ McLintock JS, Rae S, Jacobsen M. The attack rate of progressive massive fibrosis in British coalminers. In: Walton WH, ed. Inhaled particles III. Old Woking: Unwin Bros, 1971:933-52.

${ }^{31}$ Hurley JF, Burns J, Copland L, Dodgson J, Jacobsen M. Coalworkers' simple pneumoconiosis and exposure to dust at 10 British coalmines. Br J Ind Med 1982;39:120-7.

${ }^{32}$ Medical Services Study Group of the Royal College of Physicians of London. Death certification and epidemiological research. $\mathrm{Br}$ Med J 1978;ii:1063-5.

${ }^{33}$ Busuttil A, Kemp IW, Heasman MA. The accuracy of medical certificates of cause of death. Health Bull 1981;39:146-52.

${ }^{34}$ Gau DW, Diehl AK. Disagreement among general practitioners regarding cause of death. $\mathrm{Br} \mathrm{Med} J$ 1982;284:239-41.

${ }^{35}$ Cochrane AL, Moore F. Death certification from the epidemiological point of view. Lancet 1981;i:742-3.

${ }^{36}$ Rogan JM, Attfield MD, Jacobsen M, Rae S, Walker DD, Walton WH. Role of dust in the working environment in development of chronic bronchitis in British coalminers. Br J Ind Med 1973;30:217-26.

${ }^{37}$ Soutar CA, Hurley JF, Gurr DC. The relationship between dust exposure and lung function in miners and ex-miners. In Bergbau-Berufsgenossenschaft. VIth International Pneumoconiosis Conference 1983. Geneva: International Labour Organisation, 1984:390-6.

${ }^{38}$ Love RG, Miller BG. Longitudinal study of lung function in coalminers. Thorax 1982;37:193-7.

${ }^{39}$ Ruckley VA, Gauld S, Chapman JS, et al. Emphysema and dust exposure in a group of coal workers. Am Rev Respir Dis 1984;129:528-32.

${ }^{40}$ Stocks P. On the death rates from cancer of the stomach and respiratory diseases in 1949-53 among coalminers and other male residents in counties of England and Wales. Br J Cancer 1962;16:592-8.

${ }^{41}$ Ashley DJB. Environmental factors in the aetiology of gastric cancer. Br J Prev Soc Med 1969;23:187-9.

${ }^{42}$ Matolo NM, Gorishek WM, Moslander V, Dixon JA. Coal mining and cancer of the stomach. Rocky Mountain Medical Journal 1972;69:44-9.

${ }^{43}$ Rockette HE. Cause specific mortality in coal miners. J Occup Med 1977;19:795-801.

${ }^{44}$ Craven JL, Baum M, West RR. Variations in gastric cancer mortality in South Wales. Clin Oncol 1979;5:341-51.

${ }^{45}$ Goldman KP. Mortality of coal-miners from carcinoma of the lung. $\mathrm{Br} J$ Ind Med 1965;22:72-7. 
${ }^{46}$ Ashley DJB. The distribution of lung cancer and bronchitis in England and Wales. Br J Cancer 1967;21:243-59.

${ }^{47}$ Liddell FDK. Mortality of British coalminers in 1961 . Br J Ind Med 1973;30:15-24.

${ }^{48}$ Costello J, Ortmeyer CE, Morgan WKC. Mortality from lung cancer in US coalminers. Am J Public Health 1974;64:222-4.

${ }^{49}$ Rooke GB, Ward FG, Dempsey AN, Dowler JB, Whitaker CJ. Carcinoma of the lung in Lancashire coalminers. Thorax 1979;34:229-33.

${ }^{50}$ Ames RG, Amandus H, Attfield M, Green FY, Vallyathan AV. Does coal mine dust present a risk for lung cancer? A casecontrol study of US coal miners. Arch Environ Health 1984;38:331-3.

${ }^{51}$ Enterline PE. A review of mortality data for American coalminers. Ann NY Acad Sci 1972;200:260-72.

${ }^{52}$ Mooney F. Coalworker's pneumoconiosis and carcinoma of the lung. Lancet 1975;i:43, ii:390.

${ }^{53}$ Dechoux J, Pivoteau C. La pneumoconiose des mineurs de charbon lorrains. Archives des Maladies Professionelles de Medecin du Travail du Securitè Sociale 1979;40:25-41.

${ }^{54}$ Office of Population Censuses and Surveys. Occupational mortality, the Registrar General's decennial supplement for England and Wales, 1970-72. London: HMSO, 1978.

55 Jacobsen $\mathrm{M}$. Lung cancer and coalworkers' pneumoconiosis. $\mathrm{Br}$ Med J 1979;ii:208.

${ }^{56}$ Schüler G, Wälchli P, Rüttner JR, Delmore M, Taylor M, Schneiper $R$. Lungenkrebshäufigkeit und Todesalter bei den Silikosetodesfällen der SUVA, 1960-1978. Soz Präventivmed 1982;27:218-9.

${ }^{57}$ Finkelstein M, Kuriak R, Suranyi G. Mortality among miners receiving workmen's compensation for silicosis in Ontario: 1940-1975. J Occup Med 1982;24:663-7.

58 Westerholm P, Ahlmark A, Massing R, Segelberg I. Silicosis and lung cancer-a cohort study. In: Bergbau-Berufsgenossenschaft. VIth International Pneumoconiosis Conference 1983. Geneva: International Labour Organisation, 1984:217-27.

59 Jacobsen M. Coalworkers' pneumoconiosis: results from epidemiological studies in Britain. In: BergbauBerufsgenossenschaft. VIth International Pneumoconiosis Conference 1983. Geneva: International Labour Organisation, 1984:92-102.

${ }^{60}$ Archibald RMcL. Introduction. In: National Coal Board Medical Service Annual Report 1982-83. London: National Coal Board, 1984.

\section{Correspondence and editorials}

The British Journal of Industrial Medicine welcomes correspondence relating to any of the material appearing in the journal. Results from preliminary or small scale studies may also be published in the correspondence column if this seems appropriate. Letters should be not more than 500 words in length and contain a minimum of references. Tables and figures should be kept to an absolute minimum. Letters are accepted on the understanding that they may be subject to editorial revision and shortening.

The journal now also publishes editorials which are normally specially commissioned. The Editor welcomes suggestions regarding suitable topics; those wishing to submit an editorial, however, should do so only after discussion with the Editor. 